\title{
Traditional and Complementary Medicine (T\&CM) Use and its Association with Diabetic Control among Diabetic Patients in a Tertiary Centre, Kuantan Pahang
}

\author{
Nurain Zainab ZA ${ }^{\mathrm{a}}$, Nur Syahirah $\mathrm{AR}^{\mathrm{a}}$, Nurtasneem $\mathrm{R}^{\mathrm{a}}$, Mohd Al-Baqlish $\mathrm{MF}^{\mathrm{b}}$, Mohd Ridzuan $\mathrm{S}^{\mathrm{b}}$, \\ Edre $M A^{c}$ \\ ${ }^{a}$ Medical Student, Kulliyyah of Medicine, International Islamic University Malaysia. \\ ${ }^{b}$ Department of Internal Medicine Kulliyyah of Medicine, International Islamic University Malaysia. \\ cDepartment of Community Medicine, Kulliyyah of Medicine, International Islamic University Malaysia.
}

\section{ABSTRACT}

INTRODUCTION: Diabetes mellitus is a major global health concern worldwide. The fact that it is a lifelong chronic illness contributes to the increasing tendency of seeking traditional and complementary medicine (T\&CM), yet study regarding this remains limited. This study aimed to measure the prevalence of T\&CM use among diabetic patients and its association with diabetic control. MATERIALS AND METHODS: A cross sectional study was conducted at Hospital Tengku Ampuan Afzan (HTAA), Kuantan between July and August 2018. Following written consent, 136 type 2 adult diabetic patients in medical ward and those attending diabetic clinic were interviewed regarding the use of T\&CM; and their blood investigation results were collected from patients' medical records. A data collection form was used as study instrument. Descriptive statistic was used to measure the prevalence while chi-square test and independent t-test were used to find associations between T\&CM use and study background and diabetic control. RESULTS: Low prevalence of T\&CM use (16.9\%) was found, predominated by retiree group $(\mathrm{p}<0.05)$. Majority of patients used T\&CM as additional treatment for diabetes $(60.9 \%)$ and the usage was influenced by friends, family members and advertisement. There was a significant difference in Glycosylated haemoglobin A1c (HbA1c) and Estimated Glomerular Filtration Rate (eGFR) levels between inpatient and outpatient T\&CM users ( $<<0.05$ ). CONCLUSION: 1 in every 6 diabetic patients in HTAA, Kuantan were using T\&CM along with conventional diabetic medications in which retirees are predominated. No associations were found between T\&CM uses and diabetic control. Outpatient T\&CM users had lower HbA1c level with higher eGFR compared to inpatient users.

KEYWORDS: Traditional \& Complementary Medicine (T\&CM), Type 2 Diabetes Mellitus, HbA1c, eGFR INTRODUCTION

Diabetes mellitus (DM) is a major global health concern worldwide. The World Health Organization (WHO) estimated that globally high blood glucose is the third highest risk factor for premature mortality, after high blood pressure and tobacco use. In Malaysia, the National Health and Morbidity Survey (NHMS) 2015 reported that the prevalence of diabetes mellitus increases from $15.2 \%$ in 2011 to $17.5 \%$ in 2015 in which undiagnosed group predominated. ${ }^{1}$ The National

Corresponding Author:

Asst. Prof. Dr. Mohd Al-Baqlish Mohd Firdaus Department of Internal Medicine, Kulliyyah of Medicine, International Islamic University Malaysia (IIUM), 25200 Kuantan, Pahang Darul Makmur, Malaysia. Tel No: +6012-3336412

Email: baqlish@iium.edu.my
Diabetes Registry 2012 showed that the majority of patients were not well controlled. Only $23.8 \%$ of type 2 diabetes mellitus (T2DM) patients achieved good glycemic control; and majority of them developed complications such as obesity and dyslipidemia. ${ }^{2}$

With high prevalence of diabetes mellitus along with its chronic nature and known complications, patient opted for traditional and complementary medicine (T\&CM) either as an alternative or concomitant with conventional therapy. ${ }^{3-6} \mathrm{~T} \& \mathrm{CM}$ is a form of healthrelated practice which includes traditional practices, homeopathy, and complementary therapies and excluding medical and dental practices with the aim to prevent, treat or manage ailment or illness; or preserve the mental and physical well- being of an individual. ${ }^{7}$ 
Globally the trend of T\&CM uses showed an increment widely. Earlier study in Taiwan showed that $61 \%$ of diabetic patients were using T\&CM. ${ }^{5}$ Similar prevalence of $62.5 \%$ was seen in in Sepang, Selangor in Malaysia. ${ }^{8}$ It was also consistent with other previous studies done in Malaysia.9-10 It was suggested that age, gender, ethnicity and economic status influence the usage of T\&CM along with the duration of diabetes and presence of co- morbidities. ${ }^{11-12}$

Despite the rise in interest of T\&CM usage among diabetic patients, earlier studies were focusing more on the outpatient instead of comparing both inpatient and outpatient T\&CM users. Besides the knowledge about possible positive and negative effects of T\&CM on diabetic controls and its interaction with the current treatments remains limited.6,13-14 Hence, our present study aimed to explore the prevalence and factors influencing the usage of T\&CM among diabetic inpatients and outpatients, and to find the association between T\&CM use and diabetic control.

\section{MATERIAL AND METHODS}

A cross-sectional study was carried out among diabetic inpatients from medical ward and outpatients attending for regular follow up at the diabetic clinic in Hospital Tengku Ampuan Afzan (HTAA), Kuantan, Pahang from 16th July to 24th August 2018.

The study involved type 2 diabetic patients aged more than 18 years with minimum of 3 months follow up at healthcare center; or after being diagnosed. The exclusion criteria included patients with psychiatric disorders and pregnant women. The sample size was calculated using Epitools epidemiological calculator (2 tailed) based on the prevalence in previous studies. ${ }^{10,15}$ The estimated sample size was 120 with confidence interval (CI) of 95\%.Considering the non-response rate of $12 \%$, the total number of respondents was 136 with 68 respondents in each diabetic inpatients and outpatients. Convenience sampling was used due to the unavailability of diabetes registry.

A face-to-face interview was conducted using a bilingual version of data collection form adapted from previous study and all the required blood results were taken from the latest hospital medical records. ${ }^{10}$ The data collection form consisted of 4 sections including:

A. Demographics and socio-economic information

B. Different treatment combinations utilized by patients

C. Blood investigations result

D. Specific reasons to start and use T\&CM

Descriptive and analytical statistics were carried out using SPSS version 25. The findings were recorded as frequencies, percentages, means and standard deviation (SD). Bi-variable analysis on categorical data was done using Chi -Square test while independent samples t-test was used for normally distributed numerical data. A $p$ value of $<0.05$ was considered statistically significant.

All related approval were obtained for this study, i.e. hospital director, Medical Research Ethics Committee (MREC) (NMRR-18-1378-42080) and International Islamic University Malaysia Research Ethics Committee (IREC).

\section{RESULTS}

\section{Demographic and socio- economic profiles}

A total of 136 patients (68 inpatients and 68 outpatients) were recruited in this study. The mean age was 58.15 years and the majority of the respondents were female (54.4\%). The demographic and socio-economic profiles of the interviewed patients were presented in Table $\mathbf{I}$.

\section{T\&CM use among diabetic patients and its association with study background characteristics}

Out of 136 respondents, $23(16.9 \%)$ were found to be T\&CM users; with 11 from inpatient and 12 from outpatient respondents $(16.2 \%$ and $17.6 \%$ respectively). A significant number of T\&CM users $(43.5 \%)$ were from retiree age group $(p<0.05)$.

\section{Reasons to start and use of T\&CM}

More than half of the T\&CM users (60.9\%) started to use T\&CM for the purpose of additional treatment for diabetes, followed by $21.8 \%$ who believed in the 
established efficacy of T\&CM. While a minority of them had family history of T\&CM use (13\%) and only 4.3\% used it in view of fewer adverse effects of T\&CM. Friends were the main influencer in T\&CM use (34.9\%),

Table I: Study Background Characteristics aof All Respondents

\begin{tabular}{|c|c|c|c|}
\hline \multicolumn{2}{|c|}{ Study background characteristics } & \multirow{2}{*}{$\frac{\mathrm{n}=136}{62}$} & \multirow{2}{*}{$\begin{array}{c}\% \\
45.6\end{array}$} \\
\hline Gender & Male & & \\
\hline & Female & 74 & 54.4 \\
\hline & Age & & \\
\hline \multirow[t]{4}{*}{ Education level } & No formal schooling & 10 & 7.4 \\
\hline & Primary school & 39 & 28.7 \\
\hline & Secondary school & 70 & 51.5 \\
\hline & Tertiary school & 17 & 12.5 \\
\hline \multirow[t]{3}{*}{ Race } & Malay & 106 & 77.9 \\
\hline & Chinese & 14 & 10.3 \\
\hline & Indian & 16 & 11.8 \\
\hline \multirow[t]{4}{*}{ Marital status } & Married & 103 & 75.7 \\
\hline & Unmarried & 7 & 5.1 \\
\hline & Divorced & 4 & 2.9 \\
\hline & Widowed & 22 & 16.2 \\
\hline \multirow[t]{4}{*}{ Work status } & Working & 45 & 33.1 \\
\hline & Housewife & 36 & 26.5 \\
\hline & Retiree & 28 & 20.6 \\
\hline & Unemployed & 27 & 19.9 \\
\hline \multirow{3}{*}{$\begin{array}{l}\text { Monthly income } \\
\text { (RM) }\end{array}$} & Low income & 98 & 72.1 \\
\hline & Middle income & 17 & 12.5 \\
\hline & High income & 21 & 15.4 \\
\hline \multirow{6}{*}{$\begin{array}{l}\text { Treatment } \\
\text { utilized by } \\
\text { patient }\end{array}$} & $\mathrm{OAD}$ & 36 & 26.5 \\
\hline & $\mathrm{OAD}+\mathrm{T} \& \mathrm{CM}$ & 5 & 3.7 \\
\hline & $\underset{n}{\mathrm{OAD}+\mathrm{T} \& \mathrm{CM}+\text { insuli }}$ & 9 & 6.6 \\
\hline & $\mathrm{OAD}+$ insulin & 53 & 39 \\
\hline & $\mathrm{T} \& \mathrm{CM}+$ insulin & 9 & 6.6 \\
\hline & insulin & 24 & 17.6 \\
\hline
\end{tabular}

*mean (SD) followed by family members and advertisement with a similar proportion $(30.4 \%)$, and health professionals $(4.3 \%)$.

Association between T\&CM use and Diabetic Control

Association between T\&CM use and diabetic control was presented in Table II. Majority of respondents had poor HbA1c level $(82.6 \%$ among T\&CM users and $86.7 \%$ among non T\&CM user) with at least moderate eGFR values of more than $30 \mathrm{~mL} / \mathrm{min} / 1.73 \mathrm{~m}^{2}(82.6 \%$ among T\&CM users and $87.6 \%$ among non T\&CM user). T\&CM use was not significantly associated with diabetic control with p-value of 0.604 for $\mathrm{HbA} 1 \mathrm{c}$ and 0.519 for eGFR.

Table II: Association between T\&CM Use and Diabetic Control

\begin{tabular}{|c|c|c|c|c|}
\hline \multirow{2}{*}{\multicolumn{2}{|c|}{ Diabetic control }} & & & \multirow{2}{*}{$\begin{array}{l}\mathrm{p}^{-} \\
\text {value }\end{array}$} \\
\hline & & $\begin{array}{l}\text { T\&CM } \\
\text { user }\end{array}$ & $\begin{array}{l}\text { non- } \\
\text { T\&C }\end{array}$ & \\
\hline \multirow{2}{*}{$\mathrm{HbA} 1 \mathrm{c}$} & Good & 4 & 15 & 0.604 \\
\hline & Poor & 19 & 98 & \\
\hline \multirow{2}{*}{ eGFR } & Good & 19 & 99 & 0.519 \\
\hline & Poor & 4 & 14 & \\
\hline
\end{tabular}

\section{Association between diabetic inpatients and outpatients T\&CM users with diabetic control}

Table III demonstrated association between diabetic inpatients and outpatients T\&CM users with diabetic control. A significant association found between diabetic inpatients and outpatients T\&CM users with HbA1c in which all the outpatient T\&CM users had poor $\mathrm{HbA1c}$ level while only $63.6 \%$ of inpatient group had poor HbA1c level. Also, a significant difference was illustrated in terms of eGFR level in which all the outpatient T\&CM users showed good eGFR level while only $63.6 \%$ of inpatient group had good eGFR level. Hence, the overall results showed that the outpatient users had poorer HbA1c level with better eGFR level compared to inpatient users. 
Table III: Association between Diabetic Inpatient and Outpatient T\&CM Users with Diabetic Control

\begin{tabular}{|c|c|c|c|c|}
\hline \multicolumn{2}{|c|}{ Diabetic control } & \multicolumn{2}{|c|}{ Diabetic patients } & \multirow[t]{2}{*}{$\mathrm{p}$-value } \\
\hline & & $\begin{array}{l}\text { Inpatient, } \\
\mathrm{n}=11(\%)\end{array}$ & $\begin{array}{c}\text { Outpatient, } \\
\mathrm{n}=12(\%)\end{array}$ & \\
\hline \multirow{2}{*}{$\mathrm{HbA} 1 \mathrm{c}$} & Good & $4(36.4 \%)$ & $0(0 \%)$ & 0.022 \\
\hline & Poor & $7(63.6 \%)$ & $12(100 \%)$ & \\
\hline \multirow{2}{*}{ eGFR } & Good & $7(63.6 \%)$ & $12(100 \%)$ & 0.022 \\
\hline & Poor & $4(36.4 \%)$ & $0(0 \%)$ & \\
\hline
\end{tabular}

\section{DISCUSSION}

Our study showed low prevalence of T\&CM users $(16.9 \%)$ among diabetic patients which was in contrast with the studies done in globally and locally. ${ }^{916-17}$ This big gap of difference may be related to the possibility of underreported cases among the users. The percentage of T\&CM users for diabetic inpatients and outpatients were comparatively similar, which were $16.2 \%$ and $17.6 \%$, respectively.

More than half of the respondents $(60.9 \%)$ started to use T\&CM as an additional treatment for diabetes which is similar to earlier study. 8,18 The positive views on T\&CM usage were its organic nature, preferences to be treated holistically and increased availability of T\&CM were among the pulling factors toward it. ${ }^{8}$

The usage of T\&CM was influenced by friends (34.9\%), followed by family and advertisements (30.4\%) and lastly by health professionals (4.3\%) which was similarly reported previously. ${ }^{10}$

Retiree was significantly found to be the predominant group of T\&CM users. This finding correlated with mean age of our respondents in which 58.15 years old reflecting the beginning of retiring age. ${ }^{19}$ Being older and retired provided them ample time to explore the T\&CM, thus influencing the purchasing behavior. ${ }^{20}$ However, this finding differed from the NHMS 2015 in which employed people tend to use T\&CM more compared to the retirees. ${ }^{3}$ This discrepancy could be explained by the different study population and methodology of research used.

Older, married, female patients with higher levels of education and household income were more likely to be the T\&CM users in some studies. ${ }^{11-12,18,21}$ However, the present study found no significant relationship between T\&CM use with gender, mean age, ethnic group, education level, marital status and household income.

The plausible explanation for this could be that our study population was diabetic patients, who might be more likely resorting for T\&CM therapies regardless of age, gender or socio-demographic status. ${ }^{8}$ It was reported in the United States that diabetic patients were 1.6 times more likely to use T\&CM than non-diabetics. ${ }^{22}$ Besides, the result might be influenced by our smaller sample size, along with the smaller percentage of T\&CM users $(16.9 \%)$ in this present study.

No significant association was found between T\&CM use with level of $\mathrm{HbA1c}$ and eGFR. Similar findings were reported in the local and global data. $8,10,23$ However, the result was inconclusive as other cofounding factors should be taken into consideration as the compliance, treatment modalities and pharmacology effect of oral anti-diabetic drugs (OAD) and insulin could affect the HbA1c as well as other parameters that also can affect the eGFR. ${ }^{10,24-25}$

Among T\&CM users, $83 \%$ of them had poor HbA1c level with good eGFR. This was possibly due to hyperglycemic effect in early stage diabetes, causing glomerular hyperfiltration. ${ }^{26}$ However, this finding could not be generalized as the duration of illness was not specified in this study. Looking at each parameter, when comparing between inpatient and outpatient T\&CM users, a significant difference was illustrated in terms of HbA1c and eGFR. The outpatient group was significantly having poorer $\mathrm{HbA1c}$ level compared to inpatients. In contrary, inpatients T\&CM users recorded a poorer eGFR than outpatients, reflecting more severe stage of chronic kidney disease. It was reported previously that the risk of developing kidney failure increased with consumption of herbal supplements. ${ }^{13}$ The kidney function itself could be exacerbated with the chronicity of the disease itself along with other comorbid conditions in hospitalized patients. 


\section{CONCLUSION AND RECOMMENDATION}

This study revealed low prevalence of T\&CM use among diabetic patients $(16.9 \%)$ with retiree group of respondents predominated. Majority of them used T\&CM as additional treatment for diabetes; with friends, family members and advertisement as the main influential factors in starting and using T\&CM. T\&CM use was not significantly associated with diabetic control. However, a noticeable difference in HbA1c \& eGFR level was reported between inpatient and outpatient T\&CM users.

Although low prevalence of T\&CM users was demonstrated, this issue could not be taken lightly. The findings in this study could be used to improve healthcare professional awareness in considering other potential risks and benefits of T\&CM therapies; hence providing more information to the patients as well as to their family members regarding T\&CM. Also, in managing this issue, a more focused approach should be targeted to the identified group. Lastly, future research should be conducted as randomized clinical trial to provide strong evidence-based findings in terms of efficacy and effectiveness of T\&CM specifically on diabetic control.

\section{REFERENCES}

1. Institute for Public Health (IPH) 2015. National Health and Morbidity Survey 2015 (NHMS 2015). Vol. II: Non-Communicable Diseases, Risk Factors \& Other Health Problems; 2015.

2. Feisul MI, Azmi S. (Eds). National Diabetes Registry Report, Volume 1, 2009-2012. Kuala Lumpur; Ministry of Health Malaysia; 2013 Jul.

3. Institute for Public Health (IPH) 2015. National Health and Morbidity Survey 2015 (NHMS 2015). Vol. IV: Traditional \& Complementary Medicine; 2015.

4. Wanchai A, Phrompayak D. Ausanee Wanchai and Duangjai Phrompayak Patient Experiences using Complementary and Alternative Medicine for Type 2 Diabetes Mellitus in Thailand. Pacific Rim Int J Nurs Res. 2017;21(4):331-40.

5. Chang HA, Wallis M, Tiralongo E. Use of Complementary and Alternative Medicine among
People with Type 2 Diabetes in Taiwan: A CrossSectional Survey. Evidence-Based Complement Altern Med [Internet]. 2011;2011:1-8. Available from: http:/ /www.hindawi.com/journals/ ecam/2011/983792/

6. Nahas R. for the Treatment of Type 2 Diabetes. Eur J Intern Med [Internet]. 2009;55(1):591-6. Available from: http://www.ncbi.nlm.nih.gov/ pubmed/17223037

7. Medicine C. LAWS OF MALAYSIA Act 775 TRADITIONAL AND COMPLEMENTARY MEDICINE ACT 2016. Percetakaan Nas Malaysia Berhad [Internet]. 2016;1-49. Available from: http://www.federalgazette.agc.gov.my/ outputaktap/aktaBI_20160310_JW006216Act775 -BI.pdf

8. Ching SM, Zakaria ZA, Paimin F, Jalalian M. Complementary alternative medicine use among patients with type 2 diabetes mellitus in the primary care setting: A cross-sectional study in Malaysia. BMC Complement Altern Med. 2013;13.

9. Baharom N, Shamsul Azhar S, Rotina A. Prevalence of complementary alternative medicine use among patients with type II diabetes in Negeri Sembilan, Malaysia. Med Heal. 2016;11(2):257-66.

10. Hasan SS, See CK, Choong CLK, Ahmed SI, Ahmadi K, Anwar M. Reasons, perceived efficacy, and factors associated with complementary and alternative medicine use among Malaysian patients with HIV/AIDS. J Altern Complement Med [Internet]. 2010;16(11):1171-6. Available from: http://www.ncbi.nlm.nih.gov/pubmed/20973734

11. Naja F, Mousa D, Alameddine M, Shoaib H, Itani L, Mourad Y. Prevalence and correlates of complementary and alternative medicine use among diabetic patients in Beirut, Lebanon: A cross-sectional study. BMC Complement Altern Med. 2014;14(1):1-11.

12. Sundarmurthy D, Devarashetty V, S. N. Complementary and alternative medicine: practice and perspective of allopathic doctors at a tertiary care hospital. Int J Basic Clin Pharmacol. 2016;5 (5):1995-2000.

13. Lai MN, Lai JN, Chen PC, Hsieh SC, Hu FC, Wang J Der. Risks of Kidney Failure Associated With Consumption of Herbal Products Containing Mu Tong or Fangchi: A Population-Based 
Case-Control Study. Am J Kidney Dis [Internet]. 2010;55(3):507-18. Available from: http:/ / dx.doi.org/10.1053/j.ajkd.2009.10.055

14. Eddouks M, Bidi A, El Bouhali B, Hajji L, Zeggwagh NA. Antidiabetic plants improving insulin sensitivity. J Pharm Pharmacol. 2014;66 (9):1197-214.

15. Koren R, Lerner A, Tirosh A, Zaidenstein R, ZivBaran T, Golik A, et al. The use of complementary and alternative medicine in hospitalized patients with type 2 diabetes mellitus in Israel. J Altern Complement Med. 2015;21(7):395-400.

16. Peltzer K, Pengpid S. Utilization and practice of traditional/complementary/alternative medicine (T/CAM) in southeast asian nations(ASEAN) member states. Stud Ethno-Medicine. 2015;9 (2):209-18.

17. Mahfudz AS, Chan SC. Use of complementary medicine amongst hypertensive patients in a Public Primary Care Clinic in Ipoh. Med J Malaysia [nternet]. 2005;60(4):454-9. Available from: http://www.embase.com/search/results? subaction $=$ viewrecord $\&$ from $=$ export $\&$ id $=\mathrm{L} 44159$ 360\%5Cnhttp://sfxhosted.exlibrisgroup.com/ sfxtul? sid=EMBASE\&issn $=03005283 \& i d=$ doi:\&atitle $=$ Use + of + complementary + medicine + a mongst + hypertensive + patients + in $+a+$ Public + Pri mary + Care $+\mathrm{Cl}$

18. Medagama AB, Bandara R, Abeysekera RA, Imbulpitiya B, Pushpakumari T. Use of complementary and alternative medicines (CAMs) among type 2 diabetes patients in Sri Lanka: A cross sectional survey. BMC Complement Altern Med. 2014;14(1):1-5.

19. Preparations : Malaysian Perspective New Retirement Policy and Impact Towards Public Sector Employee Retirement Preparations: Malaysian. 2018; February.

20. Shih CC, Huang LH, Yeh CC, Lane HL, Hsieh CJ, Tsai CC, et al. The prevalence, characteristics, and factors associated with purchasing Chinese herbal medicine among adults in Taiwan. BMC Complement Altern Med [Internet]. 2017;17(1):17. Available from: http://dx.doi.org/10.1186/ s12906-017-1679-2

21. Bhattacharjee P, Das L, Ghosh R, Das UK, Chakraborty M. Knowledge, attitude and practice of generic medicines among doctors in a tertiary care teaching hospital of Tripura, India. Int J Basic Clin Pharmacol. 2017;6(6):1287.

22. Egede LE, Zheng D, Ye X, Silverstein MD. The Prevalence and Pattern of Complementary and Alternative. Diabetes Care. 2002;25(2):324-9.

23. Xiang L, Jiang P, Zhou L, Sun X, Bi J, Cui L, et al. Additive Effect of Qidan Dihuang Grain, a Traditional Chinese Medicine, and Angiotensin Receptor Blockers on Albuminuria Levels in Patients with Diabetic Nephropathy: A Randomized, Parallel-Controlled Trial. Evidencebased Complement Altern Med. 2016;2016.

24. Grossman LD, Roscoe R, Shack AR. Complementary and Alternative Medicine for Diabetes. Can J Diabetes [Internet]. 2018;42:S154 61. Available from: https://doi.org/10.1016/ j.jcjd.2017.10.023

25. Zhao JY, Dong JJ, Wang HP, Shang HX, Zhang DM, Liao L. Efficacy and safety of vitamin D3 in patients with diabetic nephropathy: A meta-analysis of randomized controlled trials. Chin Med J (Engl). 2014;127(15):2837-43.

26. Rigalleau V, Lasseur C, Raffaitin C, Perlemoine C, Barthe N, Chauveau P, et al. Glucose control influences glomerular filtration rate and its prediction in diabetic subjects. Diabetes Care. 2006;29(7):1491-5. 